\begin{tabular}{|c|l|}
\hline Title & Consumption of hy poall lergenic flour prevents gluten-induced airway inflammation in Brown Norway rats. \\
\hline Author(s) & Watanabe, Jun; Tanabe, Soichi; W atanabe, Michiko; Kasai, Takanori; Sonoyama, Kei \\
\hline Citation & $\begin{array}{l}\text { Bioscience Biotechnology and Biochemistry, 65(8), 1729-1735 } \\
\text { https://doi.org/10.1271/bbb.65.1729 }\end{array}$ \\
\hline Issue Date & $2001-08$ \\
\hline Doc URL & http://hdl.handle.net/2115/14854 \\
\hline Type & article \\
\hline File Information & BB\&B65-8.pdf \\
\hline
\end{tabular}

Instructions for use 


\title{
Consumption of Hypoallergenic Flour Prevents Gluten-induced Airway Inflammation in Brown Norway Rats
}

\author{
Jun Watanabe, ${ }^{1,2, \dagger}$ Soichi Tanabe, ${ }^{3}$ Michiko Watanabe, ${ }^{3}$ Takanori Kasai, ${ }^{1}$ \\ and Kei SonOyama ${ }^{1}$ \\ ${ }^{1}$ Graduate School of Agriculture, Hokkaido University, Sapporo 060-8589, Japan \\ ${ }^{2}$ Japan Society for the Promotion of Science, Chiyoda-ku, Tokyo 102-8471, Japan \\ ${ }^{3}$ Faculty of Education, Tokyo Gakugei University, Koganei-shi, Tokyo 184-8501, Japan
}

Received January 9, 2001; Accepted March 24, 2001

\begin{abstract}
Brown Norway rats were immunized with gluten, and then fed a diet containing hypoallergenic flour or an amino acid mixture. The rats were then made to inhale a solubilized gluten to induce gluten-specific bronchial asthma. The antibody levels in the serum of rats were measured by ELISA, and cell counts were done on cytospin preparations of bronchoalveolar lavage fluid. Body weight was decreased after allergen challenge in rats fed the amino acid mixture but not in rats fed the hypoallergenic flour. Antibody levels in the serum were significantly lower in rats fed hypoallergenic flour than in those fed the amino acid mixture. Differential cell counts in the bronchoalveolar lavage fluid showed that the numbers of eosinophils, lymphocytes, and neutrophils were significantly lower in rats fed the hypoallergenic flour than in those fed the amino acid mixture. These results suggest that hypoallergenic flour actively suppresses the allergic reactions, probably by inducing oral tolerance.
\end{abstract}

Key words: hypoallergenic flour; wheat-specific allergy; allergy prevention; Brown Norway rats; IgE

The number of patients suffering from food allergy is increasing throughout the world. ${ }^{1)}$ Cereal-associated allergies are considered to be an especially serious problem, because cereals are consumed as the staple food in most countries. The main symptoms of wheat-associated allergy are eczema, urticaria, asthma, and rhinitis, which develop shortly after wheat products are eaten or inhaled. The wheat-associated asthma reaction is usually called bakers' asthma, because many employees working in bakeries or confectioneries suffer this symptom. ${ }^{2)}$ The $12-16 \mathrm{kDa}$ proteins, members of the $\alpha$-amylase/trypsin inhibitor family were identified as the major allergens in salt- soluble fractions of wheat. ${ }^{3)}$ It has been reported that IgE from patients with atopic dermatitis react not only to the salt-soluble fractions but also to saltinsoluble fractions of wheat. ${ }^{4-6)}$ We identified an IgEbinding epitope of gluten as Gln-X-Y-Pro-Pro, where $\mathrm{X}$ and $\mathrm{Y}$ are replaceable amino acid residues. $^{7,8)}$

Our laboratory has been undertaking studies to prepare hypoallergenic foods. We first developed a process for producing a hypoallergenic rice preparation, ${ }^{9,10)}$ and the product has been approved as a physiologically functional food for specified health use by The Japanese Ministry of Health and Welfare. More recently we proposed a procedure for producing hypoallergenic wheat flour. ${ }^{11)}$ This procedure includes the digestion of wheat flour with cellulase and actinase, and successfully reduces the allergenicities. ${ }^{11)}$ Because the hypoallergenic flour has poor functionalities for food processing and needs to be processed into easy-to-eat foods, we proposed methods to prepare noodles and bread. ${ }^{12)}$

Hyposensitization therapy has been thought to be an effective immunotherapy to remedy allergic reactions, and has been applied to bronchial asthma ${ }^{13)}$ and bee venom allergic patients. ${ }^{14)}$ It has been shown that treatment with peptides from the major cat allergen Fel d $1,{ }^{15)}$ house dust mite allergen Del p $1,{ }^{16)}$ and Japanese cedar pollen allergen Cry j $1^{17)}$ induce specific tolerance in $\mathrm{T}$ cells in mice in the same manner as the whole allergen. In human beings, treatment with $\mathrm{T}$ cell epitope peptides of Fel d 1 was clinically successful. ${ }^{18,19)}$ Because the hypoallergenic flour that we developed contains large amounts of oligopeptides, ${ }^{11)}$ we hypothesized that it could be preventive and/or curative against gluten-specific allergic reactions via allergen-specific immunotolerance.

\footnotetext{
$\dagger$ To whom correspondence should be addressed.

Fax: +81-11-706-2496; E-mail: nabe-j@chem.agr.hokudai.ac.jp

Abbreviations: BALF, bronchoalveolar lavage fluid; BSA, bovine serum albumin; CHG, chymotryptic hydrolysate of gluten; DIG, digoxigenin
} 
The Brown Norway rat model of allergic sensitization has been extensively characterized and has several inflammatory and immunological features that resemble those of asthma, including airway eosinophilic inflammation, development of bronchial hypersensitiveness, and expression of $\mathrm{TH} 2$ cytokines such as IL-4 and IL-5 in the sensitized and challenged lung. ${ }^{20,21)}$ In this study we demonstrate that the wheat gluten-specific bronchial asthma reaction can be prevented by dietary hypoallergenic flour.

\section{Materials and Methods}

Animals and diets. Five-week-old male Brown Norway rats were purchased from Charles River (Tokyo, Japan), and housed in individual cages in a temperature-controlled $\left(23 \pm 2{ }^{\circ} \mathrm{C}\right)$ room with a dark period from 1900 to 0500 . They were allowed free access to an AIN93G composition diet $^{22)}$ and water before the experiment. For the measurement of allergypreventing effect of hypoallergenic four, after seven days of consuming the AIN93G diet, rats weighing $113 \pm 1 \mathrm{~g}(\mathrm{n}=18)$ were actively immunized with gluten and divided into two groups of 9 animals. One group was fed the hypoallergenic flour diet and the other group the amino acid diet (Table 1). The amino acid composition of the amino acid mixture was same as that of wheat flour. For the comparison of the allergy-preventing effect between hypoallergenic flour and intact wheat flour, after seven days of consuming the AIN93G diet, rats weighing $114 \pm 1 \mathrm{~g}(\mathrm{n}=18)$ were actively immunized with gluten and divided into three groups of 6 animals. Rats were fed the hypoallergenic flour diet, intact flour diet, or amino acid diet (Table 1).
This study was approved by the Hokkaido University Animal Use Committee, and animals were maintained in accordance with the guidelines for the care and use of laboratory animals at Hokkaido University.

Preparation of hypoallergenic flour. Hypoallergenic flour was prepared by the method of Watanabe et al. ${ }^{11)}$ Briefly, wheat flour was hydrolyzed with cellulase (from Trichoderma viride, 86.8 units $/ \mathrm{mg}$ solid, Amano Pharmaceutical Co., Tokyo, Japan) at $50^{\circ} \mathrm{C}$ for 1 hour, and then the actinase (250 Tyr units /mg solid, Kaken Pharma Co., Nagoya, Japan) reaction was done at $40^{\circ} \mathrm{C}$ for 1 hour at $\mathrm{pH} 7.0$. The ratios of wheat flour / enzyme and water / flour were $100 / 0.5$ and 0.6 by weight, respectively.

Preparation of the gluten fraction of wheat flour. Gluten balls made from soft flour $(250 \mathrm{~g}$, Showa Sangyo Co., Tokyo, Japan, commercial name: Cleopatra) were suspended in $500 \mathrm{~mL}$ of $0.1 \mathrm{M}$ Tris$\mathrm{HCl}(\mathrm{pH} 8.6)$ containing $4 \mathrm{M}$ urea. The suspension was centrifuged, and the supernatant was dialyzed against water. The resulting dialysate was lyophilized and then pulverized.

Preparation of solubilized gluten. Because gluten is a water-insoluble protein, the chymotryptic hydrolysate of gluten ( $\mathrm{CHG}$ ) was used as the solubilized allergen for inhalation. The gluten fraction $(10 \mathrm{~g})$ was added to an aqueous solution $(100 \mathrm{~mL})$ of $\alpha$-chymotrypsin (50 mg, Sigma Chemical Co., MO, USA, type II, 40 units $/ \mathrm{mg}$ protein) and incubated at $37^{\circ} \mathrm{C}$ for 6 hours. During the reaction, the $\mathrm{pH}$ was adjusted to 8.0 every 15 minutes. The reaction mix-

Table 1. Composition of Diet

\begin{tabular}{|c|c|c|c|}
\hline \multirow{2}{*}{ Component } & \multicolumn{3}{|c|}{ Diet } \\
\hline & Hypoallergenic flour & Amino acid mixture & Intact flour \\
\hline & \multicolumn{3}{|c|}{$\mathrm{g} / \mathrm{kg}$ diet } \\
\hline Hypoallergenic flour & 700 & - & - \\
\hline Wheat starch ${ }^{1}$ & - & 627.3 & - \\
\hline Amino acid mixture ${ }^{2}$ & - & 70 & - \\
\hline Wheat flour ${ }^{3}$ & - & - & 700 \\
\hline Casein $^{4}$ & 129.5 & 129.5 & 129.5 \\
\hline Soybean oil ${ }^{5}$ & 70 & 70 & 70 \\
\hline Cellulose $^{6}$ & 50 & 50 & 50 \\
\hline Mineral mixture ${ }^{7}$ & 35 & 35 & 35 \\
\hline Vitamin mixture ${ }^{7}$ & 10 & 10 & 10 \\
\hline L-cystine ${ }^{5}$ & 3 & 3 & 3 \\
\hline Choline bitartrate $^{5}$ & 2.5 & 2.5 & 2.5 \\
\hline Sodium bicarbonate & - & 2.7 & - \\
\hline \multicolumn{4}{|c|}{$\begin{array}{l}\text { Wheat starch was purchased from Showa Sangyo Co. (Yukiwariso; Tokyo, Japan). } \\
\text { Amino acid composition of the mixture is the same as that of hypoallergenic flour. } \\
\text { Wheat flour was purchased from Showa Sangyo Co. (Cleopatra; Tokyo, Japan). } \\
\text { Casein was purchased from the New Zealand Dairy Board (ALACID; Wellington, New Zealand). } \\
\text { Soybean oil, L-cystine, choline bitartrate, and sodium bicarbonate were purchased from Wako Pure Chemical Industries, Ltd. } \\
6 \text { Cellulose was purchased from Advantec Toyo, Ltd. (Tokyo, Japan). }\end{array}$} \\
\hline
\end{tabular}


ture was centrifuged and the resulting supernatant was chromatographed on Sephadex G-15 (Pharmacia Biotech, Uppsala, Sweeden) to obtain a high molecular-weight peptide fraction (eluate from Vo to $1.5 \mathrm{Vo})$. The fraction was lyophilized and used as solubilized gluten.

Immunization and challenge. Rats were actively immunized by a subcutaneous injection of $1 \mathrm{mg} / \mathrm{rat}$ of gluten fraction suspended in $0.5 \mathrm{~mL}$ of Imject Alum (Pierce, IL, USA) into the back of the neck. At the same time, $0.2 \mathrm{~mL}$ of Bordetella pertussis vaccine (Wako Pure Chemical Industries Ltd., Osaka, Japan) containing $6 \times 10^{8}$ heat-inactivated bacilli in PBS was administered intraperitoneally as an adjuvant. Fourteen to sixteen days after immunization, the rats were made to inhale a PBS solution of $3 \%$ solubilized gluten for 10 minutes, administered by an ultrasonic nebulizer (NE-U12; Omron, Tokyo, Japan).

Antibody measurement. Serum levels of IgG1, $\operatorname{IgG} 2 \mathrm{a}$, and $\operatorname{IgE}$ specific to wheat were measured by ELISA. All assays were done in 96-well microtiter plates (Becton Dickinson, NJ, USA). For the detection of wheat-specific IgG1 and IgG2a, plates were coated overnight at $4{ }^{\circ} \mathrm{C}$ with $4 \mathrm{M}$ urea containing Tris- $\mathrm{HCl}$ extract of wheat flour. Plates were blocked with PBS containing $2 \%$ bovine serum albumin (BSA) at $37^{\circ} \mathrm{C}$ for 1 hour. Test sera diluted with PBS containing $0.2 \%$ BSA and $0.02 \%$ Tween-20 (PBS/ BSA-Tween) were then added and incubated at $37^{\circ} \mathrm{C}$ for 2 hours. After the incubation, horseradish peroxidase-conjugated mouse anti-rat IgG1 (MARG1-2, Zymed, CA, USA), or mouse anti-rat IgG2a (MARG2a-1, Zymed) in PBS/BSA-Tween was added and incubated at $37^{\circ} \mathrm{C}$ for 2 hours. Between each step, the wells were washed five times with PBS containing $0.02 \%$ Tween-20 (PBS-Tween). Plates were developed at room temperature after the addition of $o$-phenylenediamine $(0.4 \mathrm{mg} / \mathrm{mL})$ and hydrogen peroxide $(0.016 \%)$ in citrate-phosphate buffer $(\mathrm{pH}$ 5.0). Finally, $2 \mathrm{M} \mathrm{H}_{2} \mathrm{SO}_{4}$ was added, and the absorbance at $490 \mathrm{~nm}$ was measured with a microplate reader (Model 550; Bio-Rad, CA, USA).

To detect wheat-specific IgE, plates were coated overnight at $4^{\circ} \mathrm{C}$ with mouse anti-rat IgE (MARE-1, Zymed) in carbonate buffer (pH 9.6). After blocking, diluted serum samples were added and incubated at $37^{\circ} \mathrm{C}$ for 2 hours. After the incubation, digoxigenin (DIG)-labeled solubilized gluten in PBS/BSA-Tween was added and incubated at $37^{\circ} \mathrm{C}$ for 2 hours. The DIG labeling kit was purchased from Roche (Mannheim, Germany), and coupling to solubilized gluten was done by the manufacturer's instructions. The horseradish peroxidase-conjugated anti-DIG Fab fragment (Roche) in PBS/BSA-Tween was added and incubated at $37^{\circ} \mathrm{C}$ for 1 hour. Color de- velopment and measurement were as described for the wheat-specific $\operatorname{IgG} 1$ and $\operatorname{IgG} 2 \mathrm{a}$.

The absorbance units of the diluted test samples were confirmed empirically as tripled concentrations.

Bronchoalveolar lavage and cell counting. Twentyfour hours after gluten challenge, the animals were anesthetized by an intraperitoneal injection of Nembutal (sodium pentobarbital $50 \mathrm{mg} / \mathrm{kg}$ body weight; Abbott Laboratories, IL, USA). Following laparotomy, the rats were killed by bleeding from the abdominal aorta and blood samples were collected for antibody measurement. The tracheae were then catheterized, and bronchoalveolar lavage was done with $5 \times 5 \mathrm{~mL}$ of Hanks' balanced salt solution (Gibco BRL, MD, USA). The lavage fluid was centrifuged, and the cell pellets were suspended in $1 \mathrm{~mL}$ of RPMI1640 (Gibco BRL). The cell suspension was diluted with Türk solution (Wako Pure Chemical Industries Ltd.), and total cell counts were done with a hemocytometer. Differential cell counts were done using cytospin preparations stained with May-Grünwald-Giemsa. In each sample at least 500 cells were identified according to standard structures as alveolar macrophages, eosinophils, lymphocytes, neutrophils, or other cells.

Statistical analysis. Values in the text are means \pm SEM. Student's $t$ test and Duncan's multiple range test were applied to compare the mean values among two and three groups, respectively. A $p$ value of less than 0.05 was accepted as statistically significant.

\section{Results}

\section{Body weight change after gluten challenge}

The initial body weights of the two groups were the same and averaged $113 \pm 1 \mathrm{~g}$. Body weight gains per 14 days were the same, $74 \pm 2 \mathrm{~g}$ and $74 \pm 2 \mathrm{~g}$ for rats fed the hypoallergenic flour diet and amino acid diet, respectively. Average daily food intake was $13.8 \pm$ $0.2 \mathrm{~g}$ for rats fed the hypoallergenic flour diet, $15.3 \pm$ $0.4 \mathrm{~g}$ for those fed the amino acid diet. Intake of the hypoallergenic flour diet was significantly lower than that of amino acid diet $(p<0.05)$. Body weight decreased after gluten challenge in the amino acid diet group (change rate was $-0.77 \pm 1.50 \%$ ). In contrast, the body weight of the rats fed the hypoallergenic flour diet increased after the challenge (change rate was $2.13 \pm 0.42 \%, p<0.05$ ).

\section{Wheat-specific antibody production}

There was no detectable wheat-specific antibody in rats without immunization (data not shown). Two weeks after immunization, rats fed the hypoallergenic flour diet and those fed the amino acid diet both produced detectable levels of wheat-specific IgG1, $\operatorname{lgG} 2 \mathrm{a}$, and $\operatorname{IgE}$ antibodies. The serum levels of 
wheat-specific IgG1, IgG2a, and IgE in the hypoallergenic flour diet group were significantly lower than those in the amino acid diet group (Fig. $1, p<0.05$ ).

\section{Changes in the number of cells in bronchoalveolar lavage fluid}

The total cell number in the bronchoalveolar lavage fluid (BALF) of the hypoallergenic flour group was significantly smaller than that in the amino acid group (Fig. 2, $p<0.05$ ). Rats receiving the hypoallergenic flour showed significantly lower numbers of eosinophils, lymphocytes and neutrophils in BALF (Fig. $2, p<0.01$ ). In contrast, the number of alveolar macrophages was higher in the hypoallergenic flour group (Fig. 2, $p<0.05$ ). In a preliminary experiment, more than $95 \%$ of total cells in BALF of both nonimmunized gluten-inhaled rats and immunized BSAinhaled rats were alveolar macrophages (data not shown). Therefore the observed accumulation of eosinophils in the BALF should be considered as a

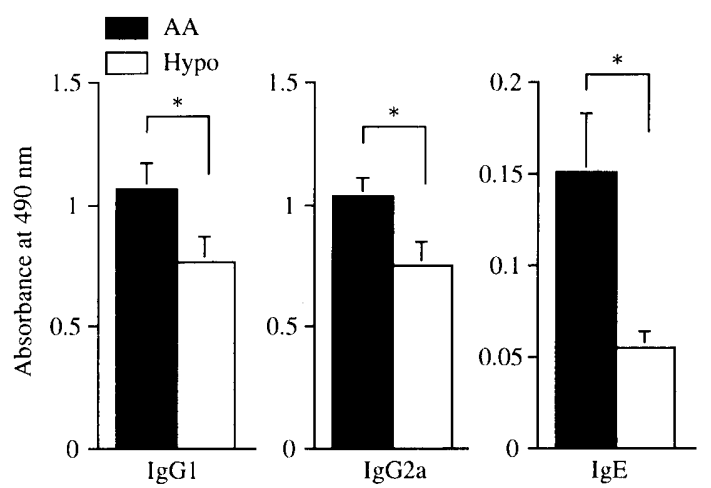

Fig. 1. Wheat-specific IgG1, IgG2a, and IgE Levels of the Amino Acid Mixture Diet Group (AA) and Hypoallergenic Flour Diet Group (Hypo) after Allergen Inhalation.

Values are given as means $\pm \mathrm{SEM}, \mathrm{n}=9$.
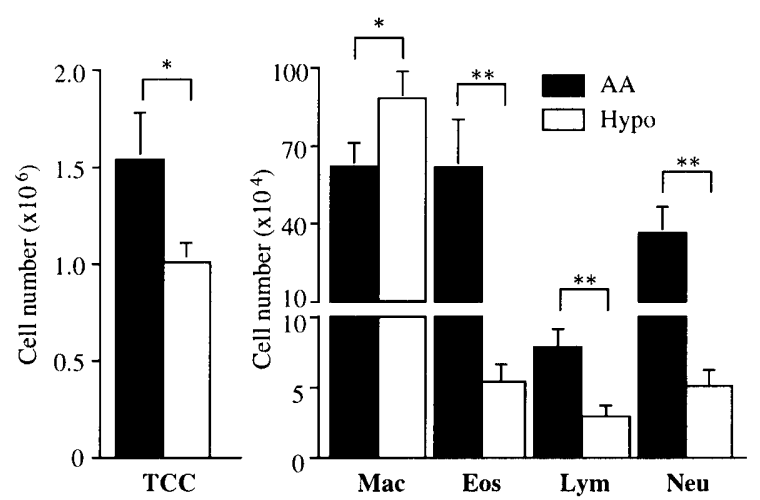

Fig. 2. Comparison of Total Cell Count and Cell Profile in BALF between Rats Fed the Amino Acid Mixture Diet (AA) and Those Fed the Hypoallergenic Flour Diet (Hypo) after Allergen Inhalation.

Values are given as means $\pm \mathrm{SEM}, \mathrm{n}=9 .{ }^{*}, p<0.05 ; * *$, $p<0.01$. TCC, total cell count; Mac, alveolar macrophages; Eos, eosinophils; Lym, lymphocytes; Neu, neutrophils. result of gluten-specific allergic reaction.

Comparison of allergy-preventing effect between hypoallergenic flour and intact wheat flour

The serum levels of wheat-specific IgG1 and IgG2a in the hypoallergenic flour diet and intact flour diet groups tended to be lower than those in the amino acid diet group (Fig. 3). The serum level of IgE in the hypoallergenic flour and intact flour diet groups was significantly lower than that of amino acid diet group (Fig. 3, $p<0.05$ ). There was no significant difference in the serum wheat-specific antibody level between hypoallergenic flour diet group and intact flour diet group. The total cell count in the BALF of the hypoallergenic flour diet and intact flour diet groups was smaller than that in the amino acid group, but the difference was not significant (Fig. 4).

\section{Discussion}

Brown Norway rats are known as a high IgE responder strain ${ }^{23,24)}$ and are used as a model of bronchial asthma because sensitized rats have been reported to show airway hyperresponsiveness and eo-

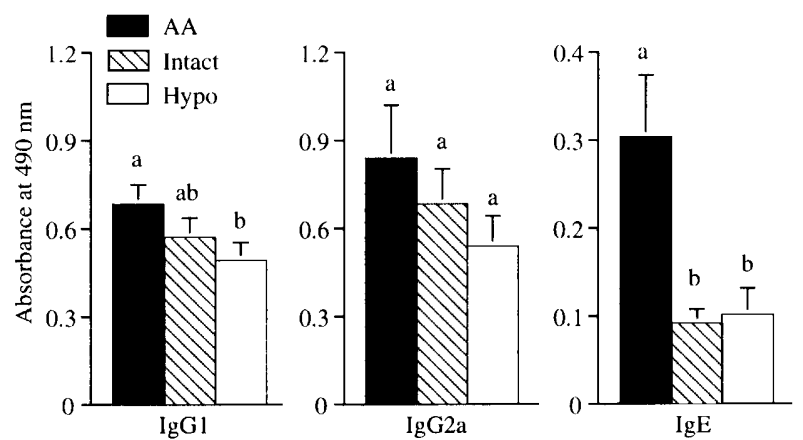

Fig. 3. Wheat-specific IgG1, IgG2a, and IgE Levels of the Amino Acid Mixture Diet Group (AA), Hypoallergenic Flour Diet Group (Hypo) and Intact Flour Diet Group (Intact) after Allergen Inhalation.

Values are given as means $\pm \mathrm{SEM}, \mathrm{n}=6$. Values with different letters are significantly different $(p<0.05)$.

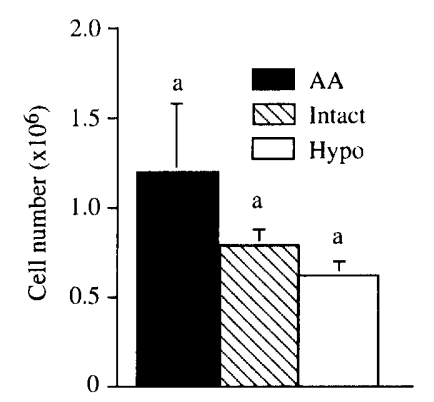

Fig. 4. Comparison of Total Cell Count in BALF between Rats Fed the Amino Acid Mixture Diet (AA), Intact Flour Diet (Intact) and Those Fed the Hypoallergenic Flour Diet (Hypo) after Allergen Inhalation.

Values are given as means \pm SEM, $\mathrm{n}=6$ 
sinophilic inflammation after antigen exposure. ${ }^{20,21)}$ In this study, gluten-sensitized Brown Norway rats were used as an allergic airway inflammation model. For the allergen challenge, it was necessary to solubilize the gluten for its inhalation. Since we previously demonstrated that gluten solubilized by chymotryptic hydrolysis retained IgE-binding activity as demonstrated by ELISA, using serum from patients with wheat-associated atopic dermatitis, ${ }^{7)} \mathrm{CHG}$ was expected to be a good alternative to intact gluten to induce gluten-specific bronchial asthma. In our preliminary experiment, significant eosinophilic infiltration in BALF was observed in gluten-immunized rats inhaled with $\mathrm{CHG}$, while total cell count and cell profile in BALF of non-immunized rats that inhaled the solubilized gluten and gluten-immunized rats that inhaled BSA were comparable to those of untreated animals (unpublished data). These results suggest that the observed eosinophilic infiltration in BALF represents the allergic airway inflammation specific to gluten. Thus, an allergic inflammation model specific to gluten has been clearly established by using $\mathrm{CHG}$ as a solubilized allergen. Despite the fact that gluten is a major food allergen, few models for studying the gluten-specific allergic reaction have been reported. Therefore, our model will be useful for studying the gluten-specific allergic reaction.

In this study, hypoallergenic flour inhibited the decrease in body weight after challenge, which may reflect the severity of allergic inflammation. More clearly, the results demonstrated that hypoallergenic flour consumption inhibited the increase in the numbers of eosinophils, lymphocytes, and neutrophils in BALF after allergen challenge (Fig. 2). Since it has been reported that eosinophils accumulated in the airway in animal models of bronchial asthma ${ }^{25)}$ and in allergic asthma patients, ${ }^{26)}$ these results strongly suggest that hypoallergenic flour prevents glutenspecific allergic inflammatory reactions.

Oral administration of antigen effectively induces antigen-specific immunotolerance. Indeed, this study showed that consumption of intact wheat flour in gluten-immunized rats tended to suppress the rise in serum antibodies against wheat (Fig. 3) and the cell infiltration in BALF (Fig. 4) after challenge, suggesting prevention of allergic inflammation through oral tolerance. More importantly, consumption of hypoallergenic flour suppressed not only the rise in serum antibody levels against wheat, but also the cell infiltration in BALF after allergen challenge in the same extent as intact flour (Fig. 3,4). These results suggest that hypoallergenic flour contains enough of the components required for inducing oral tolerance. Hirahata et $a l{ }^{17)}$ reported that the oral administration of a dominant $\mathrm{T}$ cell determinant peptide could induce oral tolerance with resulting inhibition of $\mathrm{T}$ cell responses and antibody production in allergenprimed mice in the same manner as the whole aller- gen. Since hypoallergenic flour contains large amounts of oligopeptides, the absorbed peptides may possibly affect the immunoreactions. However further studies will be necessary to test this hypothesis. Nevertheless, we believe that the hypoallergenic flour is a better immunotolerance inducer than intact wheat flour from the viewpoint of clinical application, because the majority of wheat-allergic patients did not show allergic symptoms after hypoallergenic flour intake in a clinical test (Taniuchi, S. et al. unpublished data).

Different patterns of cytokine release are characteristic of certain subgroups of T helper cells, termed TH1 and TH2; the former secrete IL-2 and IFN- $\gamma$, while the latter secrete IL-3, IL-4 and IL-5, according to observations in mice. ${ }^{27)}$ It has been reported that the production of $\mathrm{TH} 2$ cytokines against antigen stimulation was important to the allergic asthma reaction. ${ }^{28)}$ IL-4 has been shown to be essential for inducing IgE synthesis. ${ }^{29)}$ We showed in this study that the rise in wheat-specific IgE concentration after immunization was inhibited by hypoallergenic flour consumption (Fig. 1). Thus it seems possible that hypoallergenic flour suppresses wheat-specific $\operatorname{IgE}$ production via a change in the $\mathrm{TH} 1 / \mathrm{TH}_{2}$ balance to a TH1 predominant status. In our laboratory, a more sophisticated study is currently under way to clarify the precise mechanisms of the allergy-preventing effect of hypoallergenic flour.

We have developed the hypoallergenic flour aiming not to stimulate the gluten-specific allergic reactions. Actually, our previous study demonstrated that one of the major peptides in the hypoallergenic flour did not induce histamine release from the basophils of wheat allergic patients. ${ }^{8}$ In addition, our preliminary experiment showed that inhalation of hypoallergenic flour did not induce the accumulation of eosinophils in the BALF of gluten-sensitized and amino acid-fed Brown Norway rats. These observations suggest that hypoallergenic flour does not stimulate glutenspecific allergic reactions in gluten-sensitized patients and animals. More importantly, these results suggest that hypoallergenic flour actively suppresses the allergic reactions, probably by inducing oral tolerance. Since it has been reported that initial priming of the allergen-specific $\mathrm{T}$ cell response may occur before birth, ${ }^{30)}$ allergy prevention by daily food intake will be important. Work along this line would be of both immunological and clinical importance in developing practical countermeasures to a world-wide social problem, wheat allergy.

\section{Acknowledgment}

We are grateful to Drs. Y. Yanagihara and K. Kajiwara of the National Sagamihara Hospital for their technical support. 


\section{References}

1) Yamada, K., Nishimoto, M., Inagaki, Y., Inamoto, M., Yamada, M., and Torii, S., Study of the role cereal allergens in atopic dermatitis. J. Jpn. Ped. Soc., 91, 888-895 (1987).

2) Baur, X., Degens, P. O., and Sander, I., Bakers' asthma: Still among the most frequent occupational respiratory disorders. J. Allergy Clin. Immunol., 102, 984-997 (1998).

3) Gómez, L., Martín, E., Hernández, D., SánchezMonge, R., Barber, D., Pozo, V., Andrés, B., Armentia, A., Lahoz, C., Salcedo, G., and Palomono, P., Members of the $\alpha$-amylase inhibitors family from wheat endosperm are major allergens associated with bakers' asthma. FEBS Lett., 261, 85-88 (1990).

4) Yokota, S., Tsubaki, K., Shimizu, H., Matsuyama, S., Takahashi, K., and Ikezawa, Z., Study of immune-responsiveness to wheat antigen by $\operatorname{IgG}, \operatorname{IgA}$, and $\mathrm{IgE}$ immunoblotting with sera from patients with atopic dermatitis. Acta. Derm. Venereol. Suppl., 176, 45-54 (1992).

5) Ikezawa, Z., Tsubaki, K., and Yokota, S., Effect of hypoallergenic wheat (HAW-A1) on atopic dermatitis (AD) with wheat allergy, and its antigenic analysis using sera from patients with AD. Jpn. J. Allergol., 43, 679-688 (1994).

6) Varjonen, E., Savolainen, J., Mattila, L., and Kalimo, K., IgE-binding components of wheat, rye, barley and oats recognized by immunoblotting analysis with sera from adult atopic dermatitis patients. Clin. Exp. Allergy, 22, 481-489 (1994).

7) Watanabe, M., Tanabe, S., Suzuki, T., Ikezawa, Z., and Arai, S., Primary structure of an allergenic peptide occurring in the chymotryptic hydrolysate of gluten. Biosci. Biotechnol. Biochem., 59, 1596-1597 (1995).

8) Tanabe, S., Arai, S., Yanagihara, Y., Mita, H., Takahashi, K., and Watanabe, M., A major wheat allergen has a Gln-Gln-Gln-Pro-Pro motif identified as an IgE-binding epitope. Biochem. Biophys. Res. Commun., 219, 290-293 (1996).

9) Watanabe, M., Miyakawa, J., Ikezawa, Z., Suzuki, Y., Hirao, T., Yoshizawa, T., and Arai, S., Production of hypoallergenic rice by enzymatic decomposition of constituent proteins. J. Food Sci., 55, 781-783 (1990).

10) Watanabe, M., Yoshizawa, T., Miyakawa, J., Ikezawa, Z., Abe, K., Yanagisawa, T., and Arai, S., Quality improvement and evaluation of hypoallergenic rice grains. J. Food Sci., 55, 1105-1107 (1990).

11) Watanabe, M., Watanabe, J., Sonoyama, K., and Tanabe, S., A novel method for production of hypoallergenic wheat flour by enzymatic fragmentation of constituent allergens and its processing to food items. Biosci. Biotechnol. Biochem., 64, 2663-2667 (2000).

12) Watanabe, M., Ikezawa, Z., and Arai, S., Fabrication and quality evaluation of hypoallergenic wheat flour. Biosci. Biotechnol. Biochem., 58, 2061-2065 (1994).

13) Bousquet, J., and Michel, F. B., Specific im- munotherapy in asthma: Is it effective? J. Allergy Clin. Immunol., 94, 1-11 (1994).

14) Akdis, C. A., Blesken, T., Akdis, M., Wüthrich, B., and Blaser, K., Role of interleukin 10 in specific immunotherapy. J. Clin. Invest., 102, 98-106 (1998).

15) Briner, T. J., Kuo, M. -C., Keating, K. M., Rogers, B. L., and Greenstein, J. L., Peripheral T cell tolerance induced in naive and primed mice by subcutaneous injection of peptide from the major cat allergen Fel d 1. Proc. Natl. Acad. Sci. USA, 90, 7608-7612 (1993).

16) Hoyne, G. F., O'Hehir, R. E., Wraith, D. C., Thomas, W. R., and Lamb, J. R., Inhibition of T cell and antibody response to house dust mite allergen by inhalation of the dominant $T$ cell epitope in naive and sensitized mice. J. Exp. Med., 178, 1783-1788 (1993).

17) Hirahara, K., Saito, S., Serizawa, N., Sasaki, R., Sakaguchi, M., Inouye, S., Taniguchi, Y., Kaminogawa, S., and Shiraishi, A., Oral administration of a dominant $\mathrm{T}$-cell determinant peptide inhibits allergen-specific $\mathrm{TH} 1$ and $\mathrm{TH} 2$ cell responses in Cry $\mathrm{j}$ 2-primed mice. J. Allergy Clin. Immunol., 102, 961-967 (1998).

18) Wallner, B. P., and Gefter, M. L., Immunotherapy with $\mathrm{T}$ cell-reactive peptides derived from allergens. Allergy, 49, 302-308 (1994).

19) Norman, P. S., Ohmann, J. L. Jr., Long, A. A., Creticos, P. S., Gefter, M. A., Shaked, Z., Wood, R. A., Eggleston, P. A., Hafner, K. B., Rao, P., Lichtenstein, L. M., Jones, N. H., and Nicodemus, C. F., Treatment of cat allergy with $\mathrm{T}$-cell reactive peptide. Am. J. Respir. Crit. Care Med., 154, 1623-1628 (1996).

20) Elwood, W., Lotvall, J. O., Barnes, P. J., and Chung, K. -F., Characterization of allergen-induced bronchial hyperresponsiveness and airway inflammation in actively sensitized brown-Norway rats. $\mathrm{J}$. $\mathrm{Al}$ lergy Clin. Immunol., 88, 951-960 (1991).

21) Haczku, A., Macary, P., Haddad, E. B., Huang, T. -J., Kemeny, D. M., Moqbel, R., and Chung, K. -F., Expression of Th- 2 cytokines interleukin- 4 and -5 and of Th- 1 cytokine interferon- $\gamma$ in ovalbuminexposed sensitized Brown-Norway rats. Immunology, 88, 247-251 (1996).

22) Reeves, P. G., Nielsen, F. H., and Fahey, G. C. Jr., AIN-93 purified diets for laboratory rodents: final report of the American Institute of Nutrition ad hoc writing committee on the reformulation of the AIN76A rodent diet. J. Nutr., 123, 1939-1951 (1993).

23) Pauwels, R., Bazin, H., Platteau, B., and van der Straeten, M., The effect of age on IgE production in rats. Immunology, 36, 145-149 (1979).

24) Abadie, A., and Prouvost-Danon, A., Specific and total $\mathrm{IgE}$ responses to antigenic stimuli in BrownNorway, Lewis and Sprague-Dawley rats. Immunolo$g y, 39,561-569$ (1980).

25) Huang, T. - J., Macary, P. A., Wilke, T., Kemeny, D. M., and Chung, K, -F., Inhibitory effects of endogenous and exogenous interferon- $\gamma$ on bronchial hyperresponsiveness, allergic inflammation and T-helper 2 cytokines in Brown-Norway rats. Immunology, 98, 280-288 (1999).

26) Kay, A. B., "Helper" $(\mathrm{CD} 4+) \mathrm{T}$ cells and eo- 
sinophils in allergy and asthma. Am. Rev. Respir. Dis., 145, S22-S26 (1992).

27) Mosmann, T. R., Cherwinski, H., Bond, M. W., Gieldin, M. A., and Coffman, R. L., Two types of murine helper $\mathrm{T}$ cell clone. I. Definition according to profiles of lymphokine activities and secreted proteins. J. Immunol., 136, 2348-2357 (1986).

28) Ide, K., Hayakawa, H., Yagi, T., Sato, A., Koide, Y., Yoshida, A., Uchijima, M., Suda, T., Chida, K., and Nakamura, H., Decreased expression of Th2 type cytokine mRNA contributes to the lack of allergic bronchial inflammation in aged rats. J. Immunol., 163, 396-402 (1999).

29) Del Prete, G., Maggie, E., and Parronchi, P., IL-4 is an essential factor for the IgE synthesis induced in vitro by human $\mathrm{T}$ cell clones and their supernatants. J. Immunol., 140, 4193-4198 (1988).

30) Prescott, S. L., Macaubas, C., Smallacombe, T., Holt, B. J., Sly, P. D., and Holt, P. G., Development of allergen-specific T-cell memory in atopic and normal children. Lancet, 353, 196-200 (1999). 